\title{
Adaçayı Tohumu (Salvia officinalis L.) Unu İle Zenginleştirilmiş Optimize Mısır Cipsin Depolama Yeteneklerinin Belirlenmesi
}

\author{
Determination of Storage Ability of Optimize Corn Chips Enriched with Sage Seed (Salvia \\ Officinalis L.) Flour
}

\author{
Ferhat YÜKSEL ${ }^{*}$, a , Cemalettin BALTACI ${ }^{\mathrm{b}}$ \\ Gümüşhane Üniversitesi, Mühendislik ve Doğa Bilimleri Fakültesi, Gıda Mühendisliği Bölümü, 29100, Gümüşhane
}

• Geliş tarihi / Received: 22.02.2018 • Düzeltilerek geliş tarihi / Received in revised form: 08.06.2018 • Kabul tarihi / Accepted: 25.06 .2018

\begin{abstract}
$\ddot{\mathbf{O z}}$
Bu çalışmanın amacı yüzey yanıt metodu kullanılarak optimize edilmiş, adaçayı tohumu (Salvia officinalis L.) unu ile zenginleştirilmiş mısır cipslerinin 120 gün boyunca (0-40-80. ve 120. günlerde) depolama özelliklerin incelenmesi ve bazı fizikokimyasal ile duyusal özelliklerin belirlenmesidir. Örneklerin su aktivitesi $\left(\mathrm{a}_{\mathrm{w}}\right)$, $\mathrm{a}^{*}$ ve peroksit değerleri depolama zamanı boyunca artarken kuru madde içerikleri önemli oranda azalmıştır $(p<0.05)$. Örneklerin yağ, $L^{*}$ ve $b^{*}$ içerikleri depolama boyunca önemli bir değişim sergilememiştir ( $\mathrm{p}>0.05)$. Genellikle, örneklere panelistler tarafından verilen duyusal skorlar depolama zamanı artışı ile birlikte düşmüştür. Örneklerin renk değerlerinde herhangi bir değişim yoktur, fakat tat/koku, gevreklik ve genel beğeni skorları depolama boyunca azalmıştır $(\mathrm{p}<0.05)$. Adaçayı tohumu unu ile zenginleştirilmiş mısır cipslerinin depolama özellikleri örneklerin herhangi bir koruyucu materyal içermemesinden dolayı depolama zamanından etkilenmiştir.
\end{abstract}

Anahtar kelimeler: Adaçayı tohumu unu, Depolama, Duyusal analiz, Mısır cipsi

\begin{abstract}
The aim of this study was to investigate the storage properties of corn chips enriched with sage seed (Salvia officinalis L.) for 120 days (0-40-80 and 120. Days) that optimized with response surface methodology and some physiochemical and sensory properties were to determine. The water activity, $a^{*}$ and peroxide values of samples increased with the increasing storage time while the dry matter decreased significantly ( $p<0.05)$. The oil, $L^{*}$ and $b^{*}$ content of sample did not significant change for storage ( $p>0.05)$. Generally, the sensory score of samples given by panelists decreased with increasing storage time. The color properties of samples did not change, but the tastelodor, firmness and overall acceptability scores of samples decreased during storage ( $p<0.05)$. The storage properties of corn chips enriched with sage seed flour affected from storage time because the chips did not include any preservative material.
\end{abstract}

Keywords: Sage seed flour, Sensory analysis, Storage, Corn chips

\footnotetext{
*a Ferhat YÜKSEL; fyuksel@gumushane.edu.tr; Tel: (0456) 2327543 (dâhili: 1862); orcid.org/0000-0003-1995-9820

${ }^{\mathrm{b}}$ 0000-0002-4336-4002
} 


\section{Giriş}

Çerez tipi gıdalar dünya nüfusunun büyük bir çoğunluğunun sıklıkla tükettiği ürün gruplarından birisidir (Luzardo-Ocampo vd., 2017). Cipsler, özellikle mısır ve patates cipsleri gerek ülkemizde ve gerekse tüm Dünyada severek tüketilen çerez tipi gıdalardandır. Çerez tipi gıda endüstrisi Dünyada yıllık 60 Milyar dolarlık bir pazar haline gelmiştir. En iyi müşterileri çocuklar olsa da günümüzde cipsler, başta genç nüfus olmak üzere toplumdaki her yaş grubundan insanın tüketmekten zevk aldığı gidalardır (Yuksel vd., 2014).

Piyasa da satılan cipsler genel olarak ya patates ya da misırdan üretilmektedir. Dünya çerez gıda piyasasında da bu iki ürün satışta birinci ve ikinci sırada yer almaktadır. Diğer ülkelerde alternatif çeşitleri olmasına karşın ülkemizde üretilen cipsler genelde derin yağda kızartılarak satışa sunulmaktadır. Yüksek yağ içeriği ve kızartılmış olması haricinde cipsler tahıllardan üretildikleri için besin içerikleri açısından faydalı gıdalar olarak kabul edilebilir (Kayacier vd., 2014; Rababah vd., 2011). Cips ve benzeri ürünlerde tüketici bir süre tükettiği ürünün tadını kanıksamakta ve dolayısıyla değişik çeşit arayışına gitmektedir. Bu yüzden üreticiler sürekli olarak yeni ürünler geliştirerek tüketici beğenisine sunmaya çalışmaktadır. $\mathrm{Bu}$ doğrultuda sıkça yapılan işlem ya ekstrüzyon proseslerinde olduğu gibi ürüne farklı bir şekil vermek ya da tat verici madde ilavesi ile farklı aromalarda cips elde etmektir. Derin yağda kızartılmış ürünler çerez tipi gidalar arasında en önemli grubu oluşturmaktadırlar. Gıdaların derin yağda kızartılmaları, lezzetli yiyecekleri hızlı bir şekilde hazırlamak için kullanılan çok eski bir yöntemdir (Oladejo vd., 2017; Yüksel, 2014).

İnsan beslenmesinde vazgeçilmez bir yere sahip olan yağların beslenmemizde günlük alınması gereken enerjinin $\% 30$ unu aşmaması gerektiği ve bu yağların 1/3 ünün doyamamış yağ asitlerince yüksek olan gıdalardan seçilmesinin sağlı̆̆ımız açısından olumlu etkileri olduğu söylenmiştir (Yaprak vd., 2003). Omega 3 ve Omega 6 yağ asitlerinin doymamış yağ asit ihtiyacını karşılayacağı düşünüldüğünde bu yağ asitlerince zengin gidaların beslenmemizdeki yerinin artırılmasının önemli olduğu görülmektedir.

Ballıbabagiller (Lamiaceae) familyasından salvia cinsini oluşturan kokulu bitkilere Adaçayı (Salvia) denmektedir. Değerli bir uçucu yağ ve baharat bitkisi olan adaçayının Dünyada Salvia cinsine ait yaklaşık 900 türü vardır. Bu türlerin büyük bir kısmının Amerika ve güney-batı Asya kıtalarında dağılış gösterdiği belirtilmektedir. Ticari olarak en çok yetiştirilen türün Salvia officinalis L. olduğu bilinmektedir. Aromatik bitki cenneti olan ülkemizde adaçayının üretildiği, üretimin talebi karşılamadığı durumda doğadan toplandığı belirtilmektedir (Yılmaz ve Gökduman, 2015; URL 1, 2013). Antik zamanlarda birçok hastalıkların tedavisinde kullandığı bilinen adaçayının günümüzde bu özelliğinin yanında baharat ve çay olarak da tüketildiği yaygın olarak bilinmektedir. Kurutulmuş adaçayı tohumunun ögütülerek elde edilecek unun başta mısır cipsi ve diğer tahıl cipslerinin formülasyonunda kullanılması ile hem cips endüstrisinin sürekli olarak aradığı yenilikçilik anlayışına katk1 yapacak hem de içermiş olduğu yüksek doymamış yağ asidi miktarı ile cips severlere daha sağl1klı bir ürün sunulmasına katkıda bulunacaktır.

Adaçayının içerdiği yüksek aromatik ve besinsel özellikleri ile üretilecek olan cips ürünlerinin tüketicilerin duyusal beğenilerini olumlu yönde etkileyeceği ve büyük beğeni kazanacağı düşünülmektedir. $\mathrm{Bu}$ sayede tüketicilere daha doğal ve sağlıklı bir cips ürünü tüketme firsatı sunulmuş olacaktır. Farklı salvia türlerinin (Salvia hispanica L., Salvia colurnbriaBenth, Salvia polystachya) Amerika'da gidalarda katk1 maddesi ve yağ kaynağı olarak kullanıldığı ve ayrıca tıp ürünlerinde de kullanıldığ belirtilmiştir (RendónVillalobos vd., 2012). Salvia hispanica L. (chia seed) ile üretilmiş cipslerin duyusal karakteristikleri üzerine yapılan incelemede \% 015 oranında katkılama yaptıkları ve katkılama oranı arttıkça duyusal verilerde bir azalma görüldügü, en iyi kabul oranının \% 5 oranında tohumların kullanılarak yapıldığı belirlenmiştir (Coorey vd., 2012).

\section{Amaç}

$\mathrm{Bu}$ çalışmanın amacı adaçayı tohumu unu ile üretilen misir cipsinde depolama boyunca meydana gelen bazı fiziko-kimyasal (kuru madde, ham ya $\breve{g}, \mathrm{a}_{\mathrm{w}}$, peroksit, renk $\left.\left(L^{*}, a^{*}, b^{*}\right)\right)$ ve duyusal değerlerin araştırılmasıdır. Bu kapsamda Design Expert (Version 7.0, SAS Institute. Inc. Cary, NC, USA) programı kullanılarak Box \& Behnken deneme tasarımı (15 noktalı) oluşturulmuştur (Box ve Behnken, 1960). Adaçayı tohumu unu (g/100g), kızartma sicaklığ $\left({ }^{\circ} \mathrm{C}\right)$ ve kızartma süresi faktör olarak seçilmiştir. Duyusal veriler (Genel beğeni) 1şı̆̆ında optimizasyon yapılarak en uygun deneme noktaları belirlenmiştir. Elde edilen en uygun üretim faktörlerine göre cips 
üretimi yapılmış ve 120 gün boyunca (0-40-80120 gün) oda şartlarında (modifiye atmosfer paket içerisinde) depolanarak analizler gerçekleştirilmiștir.

\section{Gereç ve Yöntem}

\subsection{Materyal ve Metot}

Proje kapsamında cips elde etmek için kullanılacak mısır (masa) unları, kızartma yağı (Mısır yağ1; \%15.29 Palmitik, \% 1.93 Stearik, \% 30.75 Oleik, \%51.35 Linoleik ve \%0.65 Linolenik yağ asidi içermektedir) ile diğer temel katk1 maddeleri piyasadan temin edilmiştir. Cips formülasyonunda kullanılacak olan adaçayı tohumu (Salvia Officinalis L.) (Adaçayı tohumu yağı; \% 10.97 Palmitik, \% 2.02 Stearik, \% 19.76 Oleik, \% 66.46 Linoleik ve \% 0.78 Linolenik yağ asidi içermektedir) ise, laboratuvar ortamında kontrollü bir şekilde kurutulmuştur. Toz haline getirilmesi için havanda ezilerek saklama kaplarında buzdolabı şartlarında muhafaza edilmiştir. Adaçayı tohumunun ve misır (masa) ununu bazı özellikleri Şekil 1 de verilmiştir. Yüzey yanı yöntemi kullanılarak cipslerin kızartılacağı kızartma sıcaklığı, süresi ve formülasyona eklenecek olan adaçayı unu parametreleri belirlenmiştir. Üretilen cipslerin duyusal analizleri gerçekleştirilmiş ve genel beğeni skorlarına göre optimizasyon çalışması yapılmıştır. $\mathrm{Bu}$ değerlere göre cips ürünleri üretilip depolanmıştır. Cips üretimi Şekil 1 'e göre yapılmıştır.

Cips üretiminde kullanılacak su oranı ön denemeler sonucunda $50 \pm 2 \mathrm{~mL}$ olarak belirlenmiştir. Hazırlanan karışım homojen bir şekilde karıştırılıp hamur elde edildikten sonra 30 $\mathrm{dk}$ streç film içerisinde dinlendirilmiştir. Dinlendirme işleminden sonra örnekler $1.00 \mathrm{~mm}$ kalınlıkta açılmış ve şekil verilerek kızartma işlemi için hazırlanmıştır. Kızartma işlemi için hassas sıcaklık ayarlı yağ banyosu kullanılmıştır (Mikrotest, Türkiye). Kızartma işlemi tamamlanmış cipsler dinlendirilmek üzere kağıt havlular üzerinde bekletilmiştir. Ardından örnekler modifiye atmosfer tekniği (azot) ile paketlenerek 120 günlük depolama işlemi başlatılmıştır. 0 (kontrol)-40-80 ve 120 . günlerde paketler açılıp örneklerin depolama analizleri gerçekleştirilmiştir.

\subsection{Cips Örneklerinin Genel Bileşim Analizleri:}

Örneklerin fizikokimyasal analizleri için literatürlerde tarif edilen yöntemler kullanılmıştır.

\subsubsection{Yă̆ Analizi}

Cips örneklerinin etüvde $105 \pm 3^{\circ} \mathrm{C}$ de 3 saat kurutulduktan sonra yağ içeriği otomatik sokslet cihazı (Büchi Universal Extraction Unit B-811, Flawil, İsviçre) kullanılarak $150 \mathrm{~mL}$ petrol eteri ilavesiyle 5 saat süreyle esktraksiyon'a tabi tutulmuştur. Ekstraksiyon sonras $105^{\circ} \mathrm{C}$ de $15 \mathrm{dk}$ bekletilmiş ve sonra desikatörde oda sıcaklığına kadar soğutulduktan sonra tartımları yapılarak hesaplamaları yapılmıştır (Yüksel, 2014).

\subsubsection{Kuru Madde Tayini}

Kuru madde miktarı için tartım kapları sabit tartıma gelmesi için $105{ }^{\circ} \mathrm{C}$ de 1 saat bekletilmiştir. Daha sonra konulan örneğin $102 \pm 3$ ${ }^{\circ} \mathrm{C}$ 'ye ayarlı firında (Nüve, İstanbul) sabit tartıma ( $>3$ saat) gelinceye kadar kurutulması ile tespit edilmiştir (Gökalp, 1995).

\subsubsection{Renk Analizi}

Örneklerin renk ölçümleri Lovibond (The Tintometer Limited, İngiltere) kolorimetre cihaz1 ile gerçekleştirilmiştir. $L^{*}$; siyahtan $(0)$ beyaza (100) kadar örneğin açıklık-koyuluk, $a^{*}$; yeşilkırmızı, $b^{*}$; sarı mavi renk değerleri ölçülmüsşür (Yüksel, 2014).

\subsubsection{Su Aktivitesi Tayini}

Su aktivitesi değerleri ise otomatik su aktivitesi tayin cihazı (Aqualab Series 3T) kullanılarak belirlenmiştir (Kaban, 2007).

\subsection{Cips Örneklerinin Peroksit Sayısı Tayini}

Peroksit sayıs1, son ürünlerden ekstraksiyon ile elde edilecek olan yağ örneklerinde AOAC (2000)'de belirtilen yönteme göre yapılmıştır. $\mathrm{Bu}$ amaçla erlen mayer içerisine tartılmış olan $5 \mathrm{~g}$ yağ örneği $10 \mathrm{~mL}$ kloroform ile çözülmüş ve $15 \mathrm{~mL}$ asetik asit ve $1 \mathrm{~mL}$ doymuş potasyum iyodür ilavesinden sonra $10 \mathrm{dk}$ karanlık ortamda ve oda sıcaklığında bekletilmiştir. Ardından $75 \mathrm{~mL}$ destile su ve birkaç damla nişasta (\%1'lik) indikatör eşliğinde $0.01 \mathrm{~N}$ ayarlı sodyum tiyosülfat ile titrasyon işlemine tabi tutulmuştur. Titrasyon bitiş noktası olan berrak renk oluşumuyla elde edilen sarfiyat aşağıdaki formülde yerine konulmuş ve aynı işlemler ayrıca kör için de tekrar edilmiştir.

Peroksit sayısi $=\frac{\left[\left(\mathrm{V}_{1}-\mathrm{V}_{0}\right) \times \mathrm{N}\right]}{\mathrm{M}}$ 


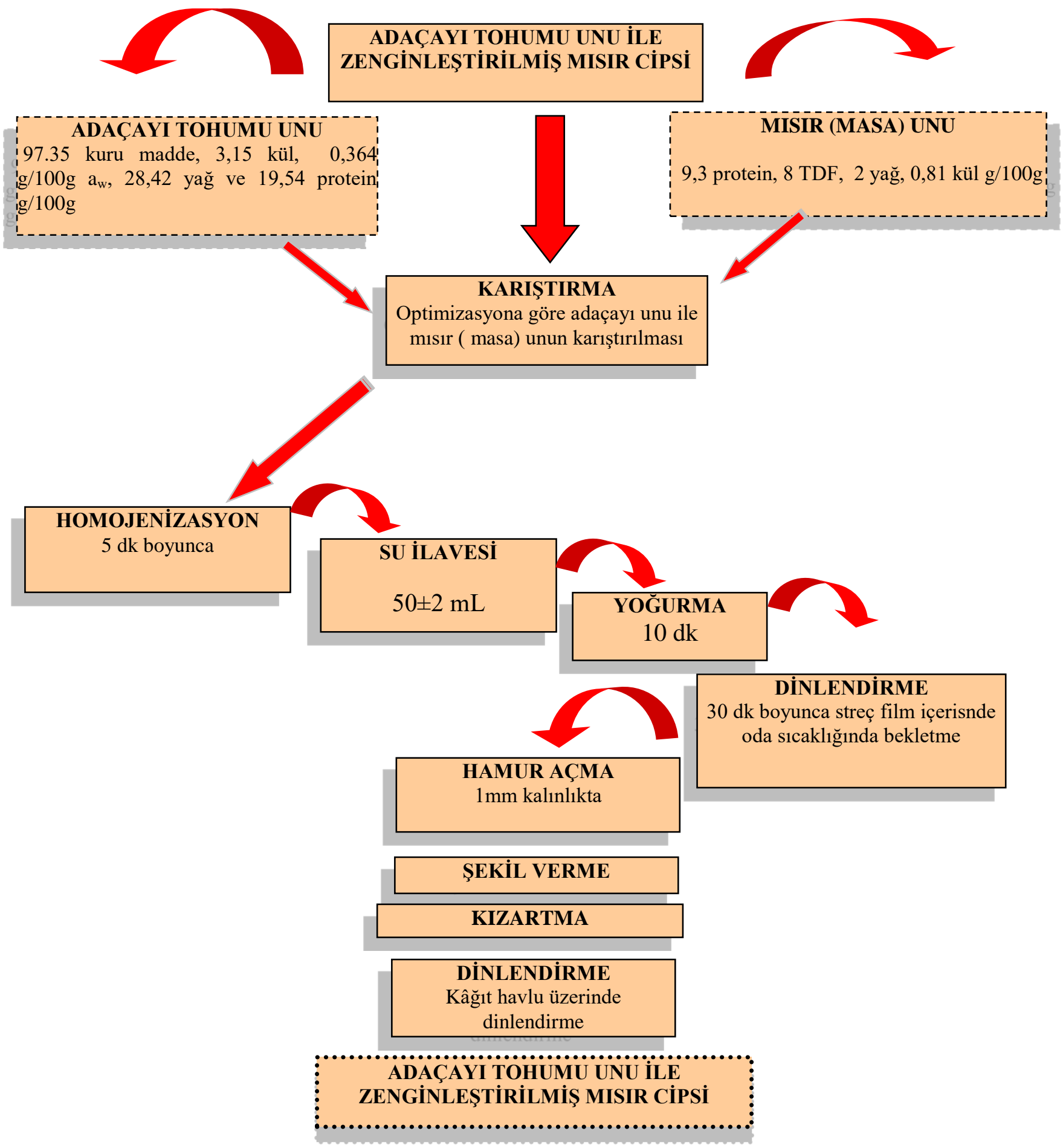

Şekil 1. Cips Üretim Şemas1

$\mathrm{V}_{1}$ ve $\mathrm{V}_{0}$ sırasıyla örnek ve kör için harcanan miktar, N, titrasyon çözeltisinin normalitesi ve $\mathrm{M}$ de örnek ağırlığıdır. Üç paralel olarak gerçekleştirilmiş olan peroksit sayısı analiz sonuçları meqO ${ }_{2} / \mathrm{kg}$ yağ şeklinde verilmiştir.

\subsection{Duyusal Analiz}

Depolanmış cips örneklerinin duyusal analizleri Gümüşhane Üniversitesi Mühendislik ve Doğa
Bilimleri Fakültesi öğrenci ve öğretim elemanlarından oluşturulmuş, eğitimli 10 kişilik bir panel grubu tarafından gerçekleştirilmiştir. Panelist grup öncelikle ürün hakkında bilgilendirildikten sonra analize başlanmıştır. Rastgele servis edilen cips örnekleri tat, koku, renk, gevreklik ve genel kabul bakımından duyusal değerlendirmelere tabi tutulmuştur. Değerlendirmede 1-9 aralığında puanlandırma 
yapılan hedonik skala kullanılmıştır (Yuksel vd., 2018).

\subsection{Depolama Süresinin Fiziko-kimyasal Sürelere Etkisi}

Elde edilen cips örneklerinin depolama özelliklerinin değerlendirilebilmesi amacıyla, depolama süresince yapısında meydana gelen bazı fiziko-kimyasal (kuru madde, renk, peroksit, yağ, aw), duyusal özelliklerdeki değişimler belirlenmiş̧ir. $\mathrm{Bu}$ amaçla, öncelikli olarak belirtilen yöntemler ve miktarlar kullanılarak (optimizasyon sonucunda) cipsler üretilmiş ve cipslerde yapılan söz konusu analizlerin tümü raf ömrü süresince de yapılmıştır. Duyusal veriler kullanılarak yüzey yanıt yöntemi ile yapılmış optimizasyon sonucuna göre en çok beğeni alan formülasyona göre üretilmiş olan cips örnekleri 120 gün süreyle depolamaya tabi tutulmuştur. Depolama amaciyla örnekler modifiye atmosfer sistemi kullanılarak azot gazı ile paketlenmiştir. Örnekler depolama süresince oda şartlarında ( 25 $\left.{ }^{\circ} \mathrm{C}\right)$ 'de muhafaza edilmiş ve bu numunelerde bütün analizler $0,40,80$ ve 120 . günlerde tekrar edilmiştir.

\section{6. İstatistiksel Analiz ve Optimizasyon}

Sonuçların istatistik değerlendirilmesi SAS 8.0 istatistiksel paket programı (SAS Institute, 1999) ile yapılmıştır. Elde edilen verilerde sonuçlar üzerine faktörlerin etkisi varyans analizi (ANOVA) ile tespit edilmiş, çoklu karşılaştırmalar ile grup ortalamaları karşılaştırılmıştır $(p=$ 0.05). Box \& Behnken ile hazırlanan deneme tasarımına göre belirlenen 15 noktalı çalışma sonucunda her bir cevap değişkenin ikinci dereceden polinom denklemi şu şekildedir (1):

$$
Y=b_{0}+\sum_{i=1}^{3} b_{i} X_{i}+\sum_{i=1}^{3} b_{i i} X_{i i}{ }^{2}+\sum_{\substack{i=1 \\ i<j}}^{3} \sum_{j=1}^{3} b_{i j} X_{i} X_{j}
$$

Denklemdeki veriler; $Y$ tahmin edilen cevap değişkenidir, $X i, X i i$ ve $X j$ (adaçayı tohumu unu, kızartma sıcaklığı ve kızartma süresi) işlem değişkenlerini gösterirken, $b 0, b i, \quad b i i, \quad b i j$ ise sabittir. Yüzey yanıt yöntemi dahilinde çalışılan duyusal parametrelerin optimum seviyeleri belirlenerek faktör seviyeleri optimize edilmiştir.

\section{Bulgular ve Tartışma}

Misır cipslerinin duyusal skorlarına göre yapılan optimizasyon çalışmasına göre (istenilirlik 1.0) en fazla tercih edilen deneme noktalar $176.45^{\circ} \mathrm{C}^{\text {' }} \mathrm{de}$
41.81 saniye kızartılan ve $8.4 \mathrm{~g} / 100 \mathrm{~g}$ adaçayı tohumu (Salvia officinalis L.) unu içeren formülasyonudur. Optimum parametrelere göre hazırlanan misir cipsleri modifiye atmosfer paketleme tekniği kullanılarak azot gazı ile paketlenmiştir. Duyusal sonuçlar ışı̆̆ında yanıt yüzey metodu ile elde edilen cips örneklerin genel beğeni yanıtları 3 numaralı denklemde verilmiştir. Genel beğeni için belirlen kararlılık katsayısı $\mathrm{R}^{2}=0.869$ olarak belirlenmiștir. Burada $\mathrm{X}_{1}$ : Adaçayı tohumu unu, $\mathrm{X}_{2}$ : kızartma sıcaklı̆ğ ve $\mathrm{X}_{3}$ : Kızartma süresini göstermektedir.

$$
\begin{aligned}
& Y=-183.35+1.06 X_{1}+1.96 X_{2}+0.58 X_{3^{-}} \\
& 0.006 X_{1} X_{2}+0.0009 X_{1} X_{3}-0.004 X_{2} X_{3}-0.003 X_{1}^{2}- \\
& 0.0005 X_{2}^{2}+0.0007 X_{3}^{2}
\end{aligned}
$$

Tablo 1 misır cipsinin 120 günlük depolama süresince belirli periyotlar ile kuru madde, yağ, peroksit ve su aktivitesi değerlerindeki değişimi göstermektedir. Depolama süresince misır cipsi örneklerinin kuru madde değerleri 96.48-98.76 $\mathrm{g} / 100 \mathrm{~g}$ aralığında bulunmuş, kuru madde değerleri depolama süresi ile orantılı olarak azaldığ 1 gözlemlenmiştir (nem içeriği artmıştır). Benzer bir çalışmayı Kayacier ve Singh, (2003) yılında Tortilla cipslerin depolanmasinda gözlemlemişlerdir. Tortilla cipslerin depolama süresince nem içeriklerin \% 18.33 den $\% 22.48 \mathrm{e}$ çıktığı belirlenmiştir (4 haftada). Örneklerin yağ değerleri ise $30 \mathrm{~g} / 100 \mathrm{~g}$ değerinin altında bulunmuş ve yağ değerleri arasındaki fark önemsiz bulunmuștur $(p>0.05)$. Örneklerin su aktivitesi değeri ise depolamayla birlikte artış göstermiş ve 120 gün sonunda başlangiçta 0.19 olan su aktivitesi değeri 120 gün sonunda 0.31 olarak kaydedilmiştir. Mısır cipsi örneklere ait peroksit değerleri depolama arttıkça önemli oranda arttığı belirlenmiştir $(p<0.05)$. Başlangıçta (0. Gün) $5.08 \mathrm{meqO}_{2} / \mathrm{kg}$ yağ olarak kaydedilen peroksit sayıs1 120 gün sonunda $28.58 \mathrm{meqO}_{2} / \mathrm{kg}$ yağ değerine ulaşmıştır. Türk gıda kodeksine göre cips gibi derin yağda kızartılmış ve yağ içeriği yüksek ürünlerde bulunması gereken peroksit değeri $10 \mathrm{meqO}_{2} / \mathrm{kg}^{\prime} 1$ geçmemesi gerekmektedir (URL-2, 2012). Buradan görüldüğü gibi kontrol gurubu örneklerin bu değere uyduğu fakat 40 . günden sonra bu değerin aşıldığ 1 belirlenmiştir. Cips ürünlerin herhangi bir koruyucu içermiyor oluşu ve kızartmalık olarak kullanılan mısır yağ ile adaçayından gelen doymamış yağ asidi içeriği peroksit değerlerini depolama ile artırdı ${ }_{1}$ söylenebilir. Yuksel (2014) tarafindan yapılan çalışmada herhangi bir koruyucunun kullanıl- 
madığı, modifiye atmosfer tekniği kullanılarak optimizasyonu yapılmış mısır cipslerinde yapılan depolamalarda, 120. gün sonunda peroksit değerlerin önemli ölçüde arttığını belirlemiştir. Sulaeman vd., (2010) yılında derin yağda kızartılmış havuç cipsleri ve onların depolama üzerine etkileri adlı yaptıkları çalışmada bizim çalışmamıza benzer sonuçlar bulmuşlardır. Depolama zamanına bağlı olarak örneklerin su aktiviteleri artmış, yağ içerikleri değişmemiş ve peroksit değerlerinde de artışlar tespit etmişlerdir. Farklı darı buğdayları ile zenginleştirilmiş yumurta cipsi üzerine yapılan bir çalışmada örneklerin depolamaya (4 ay) bağlı olarak $a_{w}$ değerleri 0.38 den 0.55 e çıktığını belirlemişlerdir (Yashoda vd., 2008). Patates cipsleri üzerine yapılan başka bir çalışmada kontrol gurubu örneklerin peroksit değerleri 0 . ve 90 . Gün de sırasılyla şu şekilde bulunmuştur; 1.69 ve 34.32 meqO $\mathrm{O}_{2} / \mathrm{kg}$ (Rababah vd., 2012).

Patates cipslerinin oksidatif stabilitesi üzerine yapılan bir çalışmada cips örneklerin depolamaya bağlı olarak peroksit içeriklerinde artışlar olduğu görülmüştür. Özellikle pamuk yağı ve soya yağı ile hazırlanan cipslerde peroksit değerlerin depolama süresince önemli miktarda yükseldiği belirlenmiştir (Lolos vd., 1999). Çalışma kapsamında kızartma işlemi için kullanılan mısır yağının yağ asidi kompozisyonu pamuk yağı ve soya yağınınkine benzediğinden örneklerde depolamaya bağlı olarak peroksit değerlerinin yükselmesinin yapılan bu çalışma ile aynı özellikte olduğu görülmüştür.

Mısır cipsi örneklerinin 120 günlük depolama süresince parlaklık $\left(L^{*}\right)$ ve kirmızılik $\left(a^{*}\right)$ değerlerinde çok önemli değişimler meydana gelmiştir $\quad(p<0.05)$, ancak sarılık $\left(b^{*}\right)$ değerlerindeki değişimler önemsiz bulunmuştur $(p>0.05)$. Parlaklık değerleri 48.98-51.94 aralığında, kırmızılık değerleri 5.85-7.95 aralığında, sarılık değerleri ise 31.61 ile 33.30 aralı̆̆ında değişim göstermiştir (Tablo 2). Örneklerin renk değerleri incelendiğinde $L^{*}$ ve $a^{*}$ değerlerinde bulunan önemli değişimlerin sebebi derin yağda kızartma olduğu düşünülmektedir. Cips ürünleri gibi yüksek karbonhidrat içeren ürünlerde renk olgusu Maillard reaksiyonu ile yakından ilgilidir (Shallenberger vd., 1959; Rababah vd., 2012; Yuksel, 2017). Bu da o ürünün kızartma anındaki yağ ile olan teması ile bağlantılıdır. 40 .ve 120. günlerdeki $L^{*}$ ve $a^{*}$ değerlerindeki değişim ürünlerdeki farklı Maillard reaksiyonu seviyeleri ile açıklanabilir.

Tablo 1. Depolama süresinin fiziko-kimyasal özelliklere etkileri

\begin{tabular}{|c|c|c|c|c|}
\hline $\begin{array}{c}\text { Depolama süresi } \\
\text { (gün) }\end{array}$ & Kuru madde (g/100g) & Yă̆ (g/100g) & Peroksit (meqO $\left.\mathrm{O}_{2} / \mathbf{k g}\right)$ & Su aktivitesi $\left(\mathbf{a}_{\mathbf{w}}\right)$ \\
\hline Başlangıç (0.gün) & $98.76 \pm 0.01^{\mathrm{a}}$ & $24.89 \pm 0.14^{\mathrm{a}}$ & $5.08 \pm 0.42^{\mathrm{c}}$ & $0.19 \pm 0.01^{\mathrm{c}}$ \\
\hline 40. Gün & $98.70 \pm 0.13^{\mathrm{a}}$ & $24.69 \pm 0.01^{\mathrm{a}}$ & $13.78 \pm 0.23^{\mathrm{b}}$ & $0.23 \pm 0.01^{\mathrm{b}}$ \\
\hline 80. Gün & $98.58 \pm 0.01^{\mathrm{a}}$ & $24.09 \pm 0.22^{\mathrm{a}}$ & $17.57 \pm 4.65^{\mathrm{b}}$ & $0.21 \pm 0.01^{\mathrm{b}}$ \\
\hline 120. Gün & $96.48 \pm 0.08^{b}$ & $23.44 \pm 1.45^{\mathrm{a}}$ & $28.58 \pm 1.15^{\mathrm{a}}$ & $0.31 \pm 0.01^{\mathrm{a}}$ \\
\hline
\end{tabular}

a-c: her bir sütundaki farklı harfler örneklerin istatistiksel olarak farklı olduğunu göstermektedir $(p<0.05)$

Tablo 3 örneklerin depolama süresine bağlı olarak duyusal özelliklerinde meydana gelen değişimi ortaya koymaktadır. Örneklerin renk değerlerinde kısmi bir düşüş meydana gelmiş, ancak depolamanın renk skorları üzerine etkisi önemli bulunmamıştır $(p>0.05)$. Örneklerin gevreklik değerleri önemli seviyede azalmış, başlangıçta 7.80 iken, 120 günlük depolama sonunda 7.20'ye gerilemiştir $(p<0.05)$. Mısır cipsi örneklerinin tatkoku skorları ile genel beğeni skorları da depolamaya bağlı olarak gerilemiş, depolamanın etkisi önemli bulunmuştur $(p<0.05)$. Farklı darı unları ile zenginleştirilmiş yumurta cipslerin 4 ay depolandiktan sonra yapılan duyusal analizlerde örneklerin depolama süresi ile birlikte duyusal değerlerin azaldığını tespit etmişlerdir (Yashoda vd., 2008).
Genel olarak tüm analiz sonuçları şu şekilde değerlendirilebilir. Paketleme oda sicaklığ 1 koşullarında $0,40,80$, ve 120 . günlerde analizleri gerçekleştirilmek üzere depolanmıştır. Mısır cipsine ait depolama verileri depolama sirasinda örneğin yağ değerlerinde önemli bir değişme olmadığını ortaya koymaktadır. Örneğin kuru madde içerikleri depolamaya bağlı azalmış buna paralel olarak su aktivitesinin arttığı görülmüştür. Kuru madde, yağ, ve renk değerlerindeki $\left(L^{*}, a^{*}, b^{*}\right)$ değişim istatistiksel olarak önemli bulunsa da değişim çok sınırlı bir miktar olduğundan pratikte bir öneminin olmadı̆̆ düşünülmektedir. 
Tablo 2. Depolama süresinin renk değerlerine etkileri

\begin{tabular}{llll}
\hline Depolama süresi (gün) & $\boldsymbol{L}^{*}$ & $\boldsymbol{a}^{*}$ & $\boldsymbol{b}^{*}$ \\
\hline Başlangıç (0.gün) & $51.94 \pm 0.43^{\mathrm{a}}$ & $5.85 \pm 0.35^{\mathrm{c}}$ & $31.61 \pm 0.33^{\mathrm{a}}$ \\
40. Gün & $48.98 \pm 1.75^{\mathrm{b}}$ & $7.95 \pm 0.08^{\mathrm{a}}$ & $32.15 \pm 0.73^{\mathrm{a}}$ \\
80. Gün & $51.17 \pm 0.32^{\mathrm{a}}$ & $7.16 \pm 0.37^{\mathrm{b}}$ & $33.30 \pm 0.60^{\mathrm{a}}$ \\
120. Gün & $51.07 \pm 0.47^{\mathrm{a}}$ & $6.98 \pm 0.63^{\mathrm{b}}$ & $33.20 \pm 1.69^{\mathrm{a}}$ \\
\hline
\end{tabular}

a-c: her bir sütundaki farklı harfler örneklerin istatistiksel olarak farklı olduğunu göstermektedir $(p<0.05)$

Tablo 3. Depolama süresinin duyusal değerlendirmeye etkileri

\begin{tabular}{lllll}
\hline Depolama süresi (gün) & Renk & Gevreklik & Tat/Koku & Genel beğeni \\
\hline Başlangıç (0.gün) & $6.40 \pm 1.14^{\mathrm{a}}$ & $7.80 \pm 1.30^{\mathrm{ab}}$ & $7.60 \pm 0.89^{\mathrm{a}}$ & $7.80 \pm 0.83^{\mathrm{a}}$ \\
40. Gün & $6.60 \pm 0.54^{\mathrm{a}}$ & $8.60 \pm 0.54^{\mathrm{a}}$ & $8.00 \pm 0.70^{\mathrm{a}}$ & $8.00 \pm 0.70^{\mathrm{a}}$ \\
80. Gün & $6.40 \pm 1.14^{\mathrm{a}}$ & $7.80 \pm 0.44^{\mathrm{ab}}$ & $5.40 \pm 1.51^{\mathrm{b}}$ & $6.40 \pm 1.14^{\mathrm{b}}$ \\
120. Gün & $5.40 \pm 1.81^{\mathrm{a}}$ & $7.20 \pm 1.09^{\mathrm{b}}$ & $5.40 \pm 0.89^{\mathrm{b}}$ & $5.80 \pm 0.83^{\mathrm{b}}$ \\
\hline
\end{tabular}

a-b: her bir sütundaki farklı harfler örneklerin istatistiksel olarak farklı olduğunu göstermektedir $(p<0.05)$

Örneklerin depolama süresi arttıkça peroksit değerlerinin arttı̆̆ ve özellikle 120. gün en yüksek seviyeye ulaştığı gözlemlenmiştir. Örneğin duyusal özellikleri bakımından elde edilen skorlara göre renk içeriğinde değişim olmadığ 1 , gevreklik, tat/koku ve genel beğeni bakımından süre arttıkça azalmalar olduğu tespit edilmiştir. Depolama esnasında üründeki nem miktarının artması ve peroksit değerinin yükselmesinin örneğin duyusal özelliklerine yansıdığı anlaşılmaktadır.

\section{Sonuc}

$\mathrm{Bu}$ çalışma ile adaçayı tohumu (Salvia officinalis L.) unu ile zenginleştirilmiş mısır cipsleri üretilmiş ve duyusal skor (genel beğeni) kullanılarak optimizasyon yapılmıştır. Optimizasyona göre üretilen misır cipsin de depolama özellikleri belirlenmiştir. 120 günlük depolama sonunda örneklerin peroksit değerlerinde önemli artış gözlemlenmiştir $(p<0.05)$. Ayrica, depolama boyunca misir cipsleri duyusal analize tabi tutulmuş ve depolama süresi arttıkça panelistlerin verdiği duyusal skorlar önemli derecede azaldığı tespit edilmiştir $(p<0.05)$. Modifiye atmosfer paketleme teknolojisinin kullanıldığı bu çalışmada örneklerin peroksit değerlerinin kodekste belirtilen 10 $\mathrm{meqO}_{2} / \mathrm{kg}^{\prime} 140$. günden sonra aştığ 1 belirlenmiştir. $\mathrm{Bu}$ artışın sebebi olarak herhangi bir koruyucunun kullanılmaması ile kızartmalık olarak kullanılan mısır yağın ve adaçayı tohumundan gelen doymamış yă asit içeriğinin yüksek olması söylenebilir. $\mathrm{Bu}$ sebeple cips gibi derin yağda kızartılmış ürünlerde palm yağı gibi doymuş yağ asidi içeriği yüksek kızartmalık yağlar tercih edilmeli ve uzun süreli depolamalarda ya kimyasallar ve antioksidanlar ile ya da farklı alternatif muhafaza yöntemleri ile muhafaza edilmelerinde fayda vardır.

\section{Teșekkür}

Çalışmamızı destekleyen Gümüşhane Üniversitesi Bilimsel Araştırma Projelerine (Proje No: 16.F5115.03.02) teşekkür ederiz.

\section{Kaynaklar}

AOAC, 2000. Analyses code 990.03, Inofficial methods of analysis of AOAC International. Washington DC: Assoc Off Anal Chem, 17th Ed. 1(4): 26-27.

Box, G.E.P., ve Behnken, D.W., 1960. Some new three level designs for the study of quantitative variables. TeEchnometrics, 7 , 455-475.

Coorey, R., Grant, A.ve Jayasena, V., 2012. Effects of chia flour incorporation on the nutritive quality and consumer acceptance of chips. J Food Res., 1(4): 85-95.

Gökalp, H. Y., 1995. Et ve ürünlerinde kalite kontrolü ve laboratuvar uygulama kılavuzu. II. Bask1. Atatürk Üniversitesi, Ziraat Fakültesi, Ofset Tesisi, Erzurum.

Kaban, G., 2007. Geleneksel olarak üretilen sucuklardan laktik asit bakterileri ile katalaz pozitif kokların izolasyonu-identifikasyonu, üretimde kullanılabilme imkanları ve uçucu 
bileşikler üzerine etkileri, Doktora tezi. Atatürk Üniversitesi.

Kayacier, A.,ve Singh, K.R., 2003. Effect of mono- and diglyceride addition on baked tortilla chips and their storage properties. J Food Process Preserv., 27: 1-8.

Kayacier, A., Yuksel, F. ve Karaman, S., 2014. Response surface methodology study for optimization of effects of fiber level, frying temperature, and frying time on some physicochemical, textural, and sensory properties of wheat chips enriched with apple fiber, Food Bioprocess Technol., 7: 133-147.

Lolos, M., Oreopoulou, V. ve Tzia, C., 1999. Oxidative stability of potato chips: effect of frying oil type, temperature and antioxidants. J Sci Food Agric., 79: 15241528.

Luzardo-Ocampo, I., Campos-Vega, R., GaytanMartinez, M., Preciado-Ortiz, R., Mendoza, S., ve Loarca-Pina, G., 2017. Bioaccessibility and antioxidant activity of free phenolic compounds and oligosaccharides from corn (Zea mays L.) and common bean (Phaseolus vulgaris L.) chips during in vitro gastrointestinal digestion and simulated colonic fermentation. Food Res. Int., 100, 1, 304311.

Oladejo, O.A., Ma, H., Qu, W., Zhou, C., Wu, B., Yang, X., ve Onwude, D.I., 2017. Effects of ultrasound pretreatments on the kinetics of moisture loss and oil uptake during deep fat frying of sweet potato (Ipomeabatatas). Inn. Food Sci.Emerging Technol., 43, 7-17.

Rababah, T. M., Yücel, Y., Ereifej, K. I., Alhamad, M. N., Al-Mahasneh, M. A., Yang, W., Muhammad, A. H. ve Ismaeal, K., 2011. Effect of grape seed extracts on the physicochemical and sensory properties of corn chips during storage. J Am Oil Chem Soc., 88: 631-637.

Rababah, T. M. Feng H.ve Yang W., 2012.Fortification of potato chips with natural plant extracts to enhance their sensory properties and storage stability. JAm Oil Chem Soc., 89:1419-1425.
Rendón-Villalobos, R., Ortíz-Sánchez, A., Solorza-Feria, J. ve Hernández, C.A.T., 2012. Formulation, physicochemical, nutritional and sensorial evaluation of corn tortillas supplemented with chía seed (Salvia hispanica L.). Czech J Food Sci., 30(2): 118-125.

SAS Institute, 1999. SAS/STAT user's Guide. Release 8.0. SAS Ins. Cary, NC.

Shallenberger, R. S., Smith, O. veTreadway, R. H., 1959. Role of the sugar in the browning reaction in potato chips. Agric Food Chem., 7(4): 274-277.

Sulaeman, A., Keeler, L., Giraud, W.D., Taylor, L.S. ve Driskell, A.J., 2003.Changes in carotenoid, physicocehemical and sensory values of deep-fried carrot chips during storage.Int J Food SciTechonol., 38: 603613.

URL-1, 2013.Türkiye adaçay1 üretimi ve ihracatında dünya birincisi, https://www.haberler.com/tibbi-aromatikbitki-cenneti-turkiye-5396420-haberi/.html (07.12.2013)

URL-2, 2012. Türk gida kodeksi bitki adi ile anılan yağlar tebliği, http://www.resmigazete.gov.tr/eskiler/2012/ 04/20120412-7.htm (12.04.2012)

Yaprak, S., Karabulut, I. ve Ergin, G., 2003. Omega 3 yağ asitleri ve insan sağlığ üzerine etkileri. GIDA, 28(2): 115-122.

Yashoda, K.P.,Modi, V.K., RaoJagannatha, R. ve Mahendrakar, R.S., 2008. Eggs chips prepared by using different millet flours as binders and changes in product quality during storage. Food Control, 19: 170-177.

Yilmaz, D., ve Gökduman M.E., 2015. Adaçayı (Slavia officinalis) bitkisinin farklı nem düzeylerinde fiziko-mekanik özelliklerinin belirlenmesi. Süleyman Demirel Üniversitesi, Ziraat Fakültesi dergisi, 10(1): 73-82.

YukselF., Karaman S. ve Kayacier A., 2014. Enrichment of wheat chips with omega-3 fatty acid by flaxseed addition textural and some physicochemical properties, Food Chem., 145: 910-917. 
Yuksel, F., 2017.Effect of powder of macaroni boiling water (by-product) on textural, oil uptake, physico-chemical, sensory and morphological properties of fried wheat chips. J Food Meas., 11: 290-298.

Yüksel, F., 2014.Bayat ekmeğin kızartılmış buğday ve misır cipsinde kullanımı, Doktora Tezi, Erciyes Üniversitesi.
Yüksel, F., Akdoğan, H.B., ve Çağlar, S., 2018. Keten tohumu ile zenginleştirilmiş eriştelerin fizikokimyasal, duyusal, pişme özellikleri ve yağ asidi kompozisyonun belirlenmesi. GIDA, 43 (2): 222-230 